\title{
Predictors of podiatry utilisation in Australia: the North West Adelaide Health Study Hylton B Menz ${ }^{* 1}$, Tiffany K Gill ${ }^{2}$, Anne W Taylor ${ }^{2}$ and Catherine L Hill ${ }^{3}$
}

Address: ${ }^{1}$ Musculoskeletal Research Centre, Faculty of Health Sciences, La Trobe University, Bundoora, Victoria 3086, Australia, ${ }^{2}$ Population Research and Outcome Studies Unit, Department of Health, Adelaide, South Australia, 5000, Australia and ${ }^{3}$ Rheumatology Unit, Queen Elizabeth Hospital, Woodville, South Australia, 5011, Australia

Email: Hylton B Menz* - h.menz@latrobe.edu.au; Tiffany K Gill - tiffany.gill@health.sa.gov.au; Anne W Taylor - anne.taylor@health.sa.gov.au; Catherine L Hill - catherine.hill@nwahs.sa.gov.au

* Corresponding author

Published: 19 August 2008

Journal of Foot and Ankle Research 2008, I:8 doi:I0.I I86/I757-II46-I-8

This article is available from: http://www.jfootankleres.com/content/I/I/8

(c) 2008 Menz et al; licensee BioMed Central Ltd.

This is an Open Access article distributed under the terms of the Creative Commons Attribution License (http://creativecommons.org/licenses/by/2.0), which permits unrestricted use, distribution, and reproduction in any medium, provided the original work is properly cited.
Received: 2 June 2008
Accepted: 19 August 2008

\begin{abstract}
Background: Foot problems are highly prevalent in the community; however no large populationbased studies have examined the characteristics of those who do and do not access podiatry services in Australia. The aim of this study was to explore patterns of podiatry utilisation in a population-based sample of people aged 18 years and over living in the northwest region of Adelaide, South Australia.
\end{abstract}

Methods: The North West Adelaide Health Study is a representative longitudinal cohort study of 4,060 people randomly selected and recruited by telephone interview. The interview included questions regarding healthcare service utilisation in the past year. Data were also collected on education, income and major medical conditions.

Results: Overall, $9.5 \%$ of the total sample and $17.7 \%$ of those who reported foot pain had attended a podiatrist in the past year. Participants who had accessed podiatry treatment were more likely to be female, be aged over 45 years, be obese, and have major chronic medical conditions (osteoporosis, osteoarthritis, diabetes, cardiovascular disease and high blood pressure). Those who reported foot pain but had not accessed a podiatrist were more likely to be male and be aged 20 to 34 years.

Conclusion: Only a small proportion of people who report foot pain have accessed podiatry services in the past year. There is a need to further promote podiatry services to the general community, particularly to men and younger people.

\section{Background}

Foot pain is a highly prevalent condition reported by at least one in five people in the general population $[1,2]$. The prevalence of foot pain increases with age [1-5], is more prevalent in females $[1,2,6,7]$ and the obese $[2,8,9]$, and is associated with self-reported disability [10], inability to perform activities of daily living $[7,11,12]$ and reduced health-related quality of life $[2,13,14]$. Despite the significant impact of foot disorders, several intervention studies have shown that foot pain associated with common conditions such as corns and calluses, nail disorders and plantar fasciitis can be effectively managed with a range of conservative and surgical techniques $[15,16]$. 
The provision of foot health services to manage foot pain and disability is primarily (although not exclusively) the domain of the podiatry profession [17]. However, although several studies have evaluated foot health service provision in specialist disciplines (such as rheumatology [18-20], diabetes [21,22] and geriatrics [23-27]), few have examined the characteristics of people who do and do not access podiatry services in the general community. In the $\mathrm{UK}$, a population-based survey of 792 people aged over 60 years reported that only 33\% of those with foot problems had received podiatry treatment, with those who accessed podiatry being more likely to be female, older, and living alone [28]. Similarly, the Cheshire Foot Pain and Disability Survey of 3,417 people aged between 18 and 80 years reported that only $36 \%$ of those with disabling foot pain had accessed podiatry services in the last six months [1], which was partly attributed to a relative shortage of National Health Service podiatry resources for younger people.

In Australia, the 2004-2005 National Health Survey of 25,906 people included a question regarding consultations with health professionals in the last two weeks, and found that $6.7 \%$ of the population had consulted a podiatrist [29]. The likelihood of accessing podiatry services increased steadily with age, and those who consulted a podiatrist were twice as likely to be female. However, whether this level of access of podiatry services is adequate cannot be ascertained from these data, as the survey did not collect any information regarding the presence of foot problems. Furthermore, although data were collected on other demographic factors and major health conditions, no analyses were undertaken to compare the characteristics of those who did and did not consult a podiatrist in the last two weeks.

To the authors' knowledge, the only population-based Australian study to examine rates of podiatry utilisation in relation to need was conducted in rural south-east Queensland in 1995 [5]. This study - the West Moreton Rural Health Needs Assessment survey - involved an interviewer-administered general health survey of 600 people aged 18 years and over, and incorporated several questions regarding foot problems and health service utilisation. Of the 154 people who reported foot problems, $102(66 \%)$ had sought treatment in the previous year. However, only $16 \%$ reported receiving treatment from a podiatrist, with the majority $(71 \%)$ seeking treatment from their general practitioner. Consistent with the findings of the National Health Survey [29], women and those aged over 65 years of age were more likely to seek podiatric treatment for their foot problem.

Developing a more thorough understanding of the number and characteristics of people who do and do not consult podiatrists may assist in evaluating the adequacy of podiatry resources and help identify specific gaps in service provision. Therefore, the aim of our study was to explore patterns of podiatry utilisation in those who took part in the North West Adelaide Health Study, a population-based survey of 4,060 people aged 18 years and over living in the northwest region of Adelaide, South Australia.

\section{Methods \\ Setting and study population}

The North West Adelaide Health Study (NWAHS) was established in 2000 in the north-western region of Adelaide, South Australia [30]. The north-west region of Adelaide comprises approximately half of the population of the city of Adelaide and a third of the population of the state of South Australia. The region also reflects the demographic profile of the state, covering a broad range of ages and socioeconomic areas. The study was designed in response to a need to assess the prevalence of priority conditions and examine their progression over time in a population-based community-dwelling cohort, to inform policy decisions about health care provision in South Australia.

Participants for Stage 1 of the study (which was conducted between 2000 and July 2003) were recruited randomly from the Electronic White Pages telephone listings and an initial telephone interview was conducted. The overall response rate for an interview and attendance at the clinic assessment was $49.4 \%$. Those within each household, who were last to have a birthday and aged 18 years and over were interviewed and invited to attend a clinic assessment.

Between 2004 and 2006, Stage 2 of the study was conducted. Where possible, all participants were contacted and invited to participate in a Computer Assisted Telephone interview (CATI), a self-completed questionnaire and/or a clinic assessment. Stage 2 specifically focused on the collection of information relating to musculoskeletal conditions, with $\mathrm{n}=3,502$ respondents providing information relating to podiatry use in the telephone questionnaire and $n=3,206$ respondents attending the clinic. Ethical approval for the study was obtained from the North West Adelaide Health Service Ethics of Human Research Committee, and written informed consent was obtained from all participants.

\section{Data collection}

As part of the self completed questionnaire, information relating to demographics, smoking, self-reported prevalence of diabetes and levels of physical activity using the questions from the Australian National Health Survey [31] were collected. As part of the clinic assessment, 
height, weight, waist and hip circumference were measured, blood was taken, and all participants attending the clinic in Stage 2 were asked: "On most days do you have pain, aching or stiffness in either of your feet?". If they answered yes to this question, they were regarded to have foot pain. As part of the CATI, the self-reported prevalence of osteoporosis and cardiovascular disease were determined, as was the health service utilisation in the past 12 months.

\section{Statistical analysis}

Data were weighted by age and sex, and probability of selection within the household, to the population of the north-west suburbs of Adelaide. Analysis was undertaken using SPSS Version 15 to determine the prevalence of podiatry consultation, and associations between age, sex, body mass index (BMI), selected chronic diseases, health risk factors and musculoskeletal pain (including foot pain). Frequencies were determined for the prevalence values (foot pain and podiatry use) and demographic characteristics of the sample. Univariate and multivariate logistic regression analyses were also undertaken. Variables that were significant at $p<0.25$ at a univariate level were included in the logistic regression models as described by Hosmer and Lemeshow [32]. The multivariate logistic regression used a backwards stepwise method, with non-significant variables removed at each step. The Hosmer and Lemeshow Goodness of Fit test is an indicator of the fit of the model; a significant value indicates that the model is not a good fit for the data [32]. The Omnibus test also is a test of how well the independent variables in the model jointly predict the dependent variable. If significant, this indicates that the model is a good fit for the data [33]. Variables in the final model were significant at the level of $p<0.05$.

\section{Results}

\section{Sample characteristics}

Sample characteristics are shown in Table 1. The characteristics of the NWAHS cohort demonstrate that this is a relatively young, heavy cohort with $38 \%$ under 40 years; and the mean $\mathrm{BMI}$ in the overweight range. A previous analysis of this dataset indicated that $17 \%$ had foot pain, with those reporting foot pain more likely to be female, be aged 50 years and over, be obese and also report knee, hip and back pain [2].

\section{Prevalence and predictors of podiatry service utilisation}

Overall, $\mathrm{n}=334$ (9.5\%; 95\% CI 8.6-10.5) respondents who responded to questions regarding health service use reported that they had consulted a podiatrist in the last 12 months. Participants who had accessed podiatry treatment were more likely to be female, be aged over 45 years, have completed only secondary education, earn $\$ 20,000$ or less per year, be obese, have major chronic medical
Table I: Demographic characteristics of participants in the NWAHS.

\begin{tabular}{lc}
\hline Variable & \\
\hline Sex & \\
Male & $1718(49.1)$ \\
Female & $1784(50.9)$ \\
Age & \\
20 to 34 years & $996(28.4)$ \\
35 to 44 years & $711(20.3)$ \\
45 to 54 years & $620(17.7)$ \\
55 to 64 years & $477(13.6)$ \\
65 to 74 years & $355(10.1)$ \\
75 years and over & $344(9.8)$ \\
Education & $1450(44.5)$ \\
Secondary & $1202(36.9)$ \\
Trade/Apprentice/Certificate/Diploma & $560(17.2)$ \\
Degree & $49(1.5)$ \\
Other/not stated & \\
Income & $613(18.8)$ \\
Up to $\$ 20,000$ & $745(22.8)$ \\
$\$ 20,000-\$ 40,000$ & $697(21.4)$ \\
$\$ 40,00 I-\$ 60,000$ & $495(15.2)$ \\
$\$ 60,00 I-\$ 80,000$ & $314(9.6)$ \\
$\$ 80,00 I-\$ 100,000$ & $263(8.1)$ \\
More than $\$ 100,000$ & $133(4.1)$ \\
Not stated & \\
\hline
\end{tabular}

Note: Values are $\mathrm{n}(\%)$ unless otherwise noted.

conditions (osteoporosis, osteoarthritis, diabetes, cardiovascular disease and high blood pressure), were less likely to consume intermediate to high risk levels of alcohol, or be current smokers ( $p<0.05$, unadjusted univariate analysis) (Table 2). Sex, age, arthritis, diabetes and smoking status were confirmed as significant predictors in multivariate logistic regression (Hosmer and Lemeshow Goodness of Fit $\chi^{2}=10.96, p=0.204$; Omnibus test $\chi^{2}=295.93$, $d f=9, p<0.001$ ) (Table 3).

Of those who attended the clinic assessment and reported that they had foot pain $(\mathrm{n}=538), 17.7 \%$ (95\% CI 14.7 $21.2, \mathrm{n}=95$ ) had consulted a podiatrist in the last 12 months. Those who reported foot pain but had not accessed a podiatrist were more likely to be male, be aged 20 to 34 years, earn between $\$ 40,000$ and $\$ 60,000$ per year and be current smokers, or were less likely to have major chronic medical conditions (osteoporosis, osteoarthritis, diabetes, cardiovascular disease and high blood pressure) ( $p<0.05$, unadjusted univariate analysis) (Table $4)$. Sex and age were confirmed as significant predictors in multivariate logistic regression analyses (Hosmer and Lemeshow Goodness of Fit $\chi^{2}=4.14, p=0.844$; Omnibus test $\chi^{2}=53.57, d f=6, p<0.001$ ) (Table 5).

\section{Discussion}

The aim of this study was to examine the prevalence and predictors of podiatry service utilisation in a population- 
Table 2: Characteristics of participants who accessed podiatry services $(n=334)$ in the previous 12 months (univariate analysis).

\begin{tabular}{|c|c|c|c|c|}
\hline Variable & $\mathrm{n}$ & $\%$ & Odds ratio $(95 \% \mathrm{Cl})$ & $p$ value \\
\hline \multicolumn{5}{|l|}{ Sex } \\
\hline Male & 102 & 5.9 & 1.00 & \\
\hline Female & 232 & 13.0 & $2.38(1.86-3.03)$ & $<0.001$ \\
\hline \multicolumn{5}{|l|}{ Age } \\
\hline 20 to 34 years & 37 & 3.7 & 1.00 & \\
\hline 35 to 44 years & 35 & 4.9 & $1.36(0.85-2.18)$ & 0.206 \\
\hline 45 to 54 years & 39 & 6.3 & $1.75(1.11-2.78)$ & 0.017 \\
\hline 55 to 64 years & 52 & 10.9 & $3.20(2.07-4.96)$ & $<0.001$ \\
\hline 65 to 74 years & 60 & 17.0 & $5.35(3.48-8.22)$ & $<0.001$ \\
\hline 75 years and over & 110 & 32.1 & $12.32(8.26-18.37)$ & $<0.001$ \\
\hline \multicolumn{5}{|l|}{ Education } \\
\hline Secondary & 167 & 11.8 & 1.00 & \\
\hline Trade/Apprentice/Certificate/Diploma & 101 & 8.5 & $0.70(0.54-0.91)$ & 0.007 \\
\hline Degree or higher & 36 & 6.4 & $0.5 \mathrm{I}(0.35-0.75)$ & $<0.001$ \\
\hline Other/not stated & 5 & 10.5 & $0.88(0.34-2.25)$ & 0.787 \\
\hline \multicolumn{5}{|l|}{ Income } \\
\hline Up to $\$ 20,000$ & 94 & 15.9 & 1.00 & \\
\hline$\$ 20,001-\$ 40,000$ & 80 & 11.0 & $0.65(0.47-0.90)$ & 0.008 \\
\hline$\$ 40,001-\$ 60,000$ & 51 & 7.4 & $0.42(0.30-0.61)$ & $<0.001$ \\
\hline$\$ 60,001-\$ 80,000$ & 32 & 6.5 & $0.37(0.24-0.56)$ & $<0.001$ \\
\hline$\$ 80,001-\$ 100,000$ & 14 & 4.6 & $0.26(0.14-0.45)$ & $<0.001$ \\
\hline More than $\$ 100,000$ & 20 & 7.4 & $0.42(0.25-0.7 I)$ & 0.001 \\
\hline Not stated & 17 & 13.7 & $0.84(0.48-1.45)$ & 0.524 \\
\hline \multicolumn{5}{|l|}{ Chronic conditions } \\
\hline Osteoporosis & 37 & 28.0 & $4.04(2.72-6.01)$ & $<0.001$ \\
\hline Arthritis & 147 & 19.8 & $3.48(2.75-4.40)$ & $<0.001$ \\
\hline Diabetes & 65 & 29.4 & $4.58(3.34-6.30)$ & $<0.001$ \\
\hline Cardiovascular disease & 55 & 23.6 & $3.32(2.40-4.60)$ & $<0.001$ \\
\hline High blood pressure & 116 & 14.3 & $1.85(1.45-2.37)$ & $<0.001$ \\
\hline High cholesterol & 126 & 9.9 & $1.01(0.80-1.29)$ & 0.924 \\
\hline Obese $\left(\mathrm{BMI} \geq 30 \mathrm{~kg} / \mathrm{m}^{2}\right)$ & 108 & 11.6 & $1.31(1.03-1.68)$ & 0.031 \\
\hline \multicolumn{5}{|l|}{ Alcohol consumption } \\
\hline Non drinker (no risk) & 159 & 10.2 & 1.00 & \\
\hline Low risk & 129 & 9.7 & $0.95(0.74-1.21)$ & 0.655 \\
\hline Intermediate to very high risk & 7 & 4.1 & $0.38(0.18-0.81)$ & 0.013 \\
\hline Current smoker & 24 & 3.7 & $0.31(0.20-0.48)$ & $<0.001$ \\
\hline No physical activity (sedentary) & 79 & 9.5 & $0.99(0.76-1.31)$ & 0.967 \\
\hline
\end{tabular}

Note: The weighting of data can result in rounding discrepancies or totals not adding.

based sample of people aged 18 years and over who took part in the North West Adelaide Health Study (NWAHS). The findings indicate that $9.5 \%$ of the cohort had consulted a podiatrist in the past 12 months. Of those who reported foot pain, only $17.7 \%$ had consulted a podiatrist. Our analysis indicated that the typical podiatry patient is an older, obese woman with limited education, relatively low income, and multiple chronic diseases. In contrast, those with foot problems who have not consulted a podiatrist tended to be younger men without chronic diseases.

The total proportion of people who reported accessing podiatry services in the NWAHS (9.5\%) was higher than the 2004-2005 Australian National Health Survey (6.7\%) [31] and the West Moreton Rural Health Needs Assessment survey (3\%) [5]. The difference between the current study and the National Health Survey is most likely due to the different timeframes contained within the health care utilisation questionnaires used (previous 12 months for the NWAHS compared to the previous two weeks in the National Health Survey). However, it is also possible that the NWAHS population had greater access to podiatry than the national average. The Australian Institute for Health and Welfare's Podiatry Labour Force study estimated that in 2003, the number of full-time equivalent podiatrists per 100,000 population in South Australia was 17.4, higher than all other states included in the survey (Victoria: 13.0, Tasmania: 12.4, New South Wales: 9.3 and Queensland: 7.7) [34].

The proportion of people who reported foot pain and who had consulted a podiatrist $(17 \%)$ was substantially lower than similar studies conducted in the UK (33 to $36 \%)[1,28]$, but similar to the rate reported in the West 
Table 3: Multivariate predictors of accessing podiatry services in the last 12 months.

\begin{tabular}{|c|c|c|}
\hline Variable & Odds ratio $(95 \% \mathrm{Cl})$ & $p$ value \\
\hline \multicolumn{3}{|l|}{ Sex } \\
\hline Male & 1.00 & \\
\hline Female & $2.32(1.77-3.05)$ & $<0.001$ \\
\hline \multicolumn{3}{|l|}{ Age } \\
\hline 20 to 34 years & 1.00 & \\
\hline 35 to 44 years & $1.21(0.75-1.94)$ & 0.439 \\
\hline 45 to 54 years & $1.16(0.7 \mid-1.89)$ & 0.554 \\
\hline 55 to 64 years & $1.75(1.09-2.82)$ & 0.021 \\
\hline 65 to 74 years & $2.53(1.54-6.11)$ & $<0.001$ \\
\hline 75 years and over & $5.99(3.81-9.42)$ & $<0.001$ \\
\hline \multicolumn{3}{|l|}{ Chronic conditions } \\
\hline Arthritis & $1.65(1.23-2.22)$ & 0.001 \\
\hline Diabetes & $3.11(2.17-4.46)$ & $<0.001$ \\
\hline Current smoker & $0.46(0.29-0.73)$ & 0.001 \\
\hline
\end{tabular}

Moreton Rural Health Needs Assessment survey (16\%) [5]. In the UK, the National Health Service provides free podiatry care to approximately $4 \%$ of the population, with the majority of recipients being aged over 65 years [35]. In Australia, relatively limited podiatry services are provided by the public sector, and in most settings access to podiatry is restricted to those with "high risk" feet, i.e.: those with chronic conditions such as diabetes or rheumatoid arthritis. Subsequently, the awareness and utilisation of podiatry among older people is likely to be higher than younger people [27]. The lack of publicly-funded podiatry services for people without chronic diseases, combined with an inability or reluctance to pay for private services, may explain the very low levels of podiatry consultation in younger people (as low as 4 to $10 \%$ in those aged 20 to 44 years).

However, it is also possible that some degree of foot health service provision is currently being met by other health care professionals, particularly general practitioners. A survey of 1,130 people aged over 65 years of age in the Netherlands indicated that $30 \%$ sought foot treatment from their general practitioner rather than a podiatrist/ chiropodist [26]. Similarly, in the West Moreton Rural Health Needs Assessment survey, $71 \%$ of those with a foot problem had consulted their general practitioner, with no podiatry consultations reported by those aged 18 to 24 years [5]. Interestingly, the National Health Interview Survey in the US indicated that while treatment of corns, calluses and nail disorders were almost exclusively provided by podiatrists, management of musculoskeletal foot conditions and acute injuries (such as ankle sprains) were more likely to be managed by medical practitioners [3]. Given the high prevalence of older people accessing podiatry services, it is possible that younger people do not consider consulting a podiatrist for musculoskeletal foot conditions, as they associate podiatry with routine management of skin and nail problems in older people. If this is correct, there may be a need for the podiatry profession to promote a greater awareness of the scope of podiatry practice to young and middle-aged people.

Consistent with anecdotal observations, our results indicate that the typical patient attending podiatry is an older, obese woman with limited education, relatively low income, and multiple chronic diseases. This patient profile is not surprising given the available evidence relating to the role of increased age $[1-5]$, female sex $[1,2,6,7]$, obesity $[2,5,8,9]$ and comorbidities $[2,9,12,36]$ in the development of foot problems. The role of socio-economic status, however, is equivocal. Lower levels of education have been found to be associated with foot problems in some studies $[3,9]$ but not others $[12,13,36]$. Similarly, while some studies have found that people with foot problems have lower income levels [3] others have failed to find such an association $[9,13]$. These discrepancies are likely to reflect differences in how income levels are defined, differences in educational systems between countries, and variability in adjustment for confounders in the statistical models. Nevertheless, in the current study the association between accessing podiatry services and socio-economic factors was no longer significant after other variables were considered.

The major strength of this study is the use of a populationbased sample with excellent response rates over a broad age range. However, the findings of this study need to be interpreted in the context of several limitations. Firstly, we defined foot pain according to a single question rather than using foot-specific questionnaires, such as the Manchester Foot Pain and Disability Index [14,37] or Foot Health Status Questionnaire [38]. Secondly, we were unable to examine the participants' feet in the study to ascertain the underlying cause of their pain. Thirdly, we did not ask participants whether they had accessed other health care professionals for management of their foot pain. As such, we cannot necessarily conclude that the proportion of people with foot pain who have not accessed a podiatrist is an accurate indicator of unmet need.

Despite these limitations, the results of this study provide the first detailed insights into the number and characteristics of people who do and do not access podiatry services in Australia, based on a large representative sample. The findings may assist in the future planning and development of foot health services, and provide some direction for promotional activities for the podiatry profession. Although the important role that podiatry plays in the maintenance of foot health in older people should not be ignored, there would appear to be a large number of young to middle-aged people with foot pain who are cur- 
Table 4: Characteristics of participants who reported foot problems and did not access podiatry services $(n=443)$ in the last 12 months (univariate analysis).

\begin{tabular}{|c|c|c|c|c|}
\hline Variable & $\mathrm{n}$ & $\%$ & Odds ratio $(95 \% \mathrm{Cl})$ & $p$ value \\
\hline \multicolumn{5}{|l|}{ Sex } \\
\hline Female & 233 & 77.2 & 1.00 & \\
\hline Male & 210 & 88.9 & $2.36(1.45-3.84)$ & 0.001 \\
\hline \multicolumn{5}{|l|}{ Age } \\
\hline 75 years and over & 40 & 58.7 & 1.00 & \\
\hline 65 to 74 years & 61 & 73.4 & $1.94(0.98-3.84)$ & 0.058 \\
\hline 55 to 64 years & 87 & 84.0 & $3.69(1.81-7.52)$ & $<0.001$ \\
\hline 45 to 54 years & 105 & 86.0 & $4.32(2.14-8.74)$ & $<0.001$ \\
\hline 35 to 44 years & 62 & 89.3 & $5.85(2.38-14.37)$ & $<0.001$ \\
\hline 20 to 34 years & 88 & 95.9 & $16.43(5.26-51.28)$ & $<0.001$ \\
\hline \multicolumn{5}{|l|}{ Education } \\
\hline Secondary & 249 & 82.4 & 1.00 & \\
\hline Trade/Apprentice/Certificate/Diploma & 142 & 81.9 & $0.96(0.59-1.57)$ & 0.883 \\
\hline Degree or higher & 39 & 82.0 & $0.97(0.44-2.16)$ & 0.940 \\
\hline Other/not stated & 12 & 84.1 & $1.12(0.26-4.91)$ & 0.877 \\
\hline \multicolumn{5}{|l|}{ Income } \\
\hline$U_{p}$ to $\$ 20,000$ & 90 & 72.0 & 1.00 & \\
\hline$\$ 20,001-\$ 40,000$ & 121 & 81.8 & $1.74(0.98-3.09)$ & 0.057 \\
\hline$\$ 40,001-\$ 60,000$ & 92 & 91.0 & $3.91(1.78-8.58)$ & 0.001 \\
\hline$\$ 60,001-\$ 80,000$ & 43 & 78.8 & $1.45(0.68-3.09)$ & 0.342 \\
\hline$\$ 80,001-\$ 100,000$ & 33 & 85.4 & $2.28(0.86-6.04)$ & 0.097 \\
\hline More than $\$ 100,000$ & 35 & 91.3 & $4.09(1.23-13.52)$ & 0.021 \\
\hline Not stated & 28 & 88.5 & $2.98(0.93-9.50)$ & 0.065 \\
\hline \multicolumn{5}{|l|}{ Chronic conditions } \\
\hline Osteoporosis & 24 & 64.5 & $0.36(0.18-0.72)$ & 0.004 \\
\hline Arthritis & 173 & 75.3 & $0.42(0.26-0.66)$ & $<0.001$ \\
\hline Diabetes & 42 & 68.7 & $0.42(0.23-0.76)$ & 0.004 \\
\hline Cardiovascular disease & 36 & 68.4 & $0.42(0.22-0.79)$ & 0.007 \\
\hline High blood pressure & 134 & 76.4 & $0.57(0.36-0.90)$ & 0.015 \\
\hline High cholesterol & 186 & 80.3 & $0.76(0.49-1.19)$ & 0.235 \\
\hline Obese $\left(\mathrm{BMI} \geq 30 \mathrm{~kg} / \mathrm{m}^{2}\right)$ & 187 & 81.9 & $0.84(0.6 \mathrm{I}-\mathrm{I} .49)$ & $0.84 I$ \\
\hline \multicolumn{5}{|l|}{ Alcohol consumption } \\
\hline Non drinker (no risk) & 198 & 80.5 & 1.00 & \\
\hline Low risk & 198 & 82.8 & $1.17(0.74-1.85)$ & 0.508 \\
\hline Intermediate to very high risk & 29 & 95.1 & $4.68(0.89-24.76)$ & 0.068 \\
\hline Current smoker & 90 & 92.6 & $3.14(1.42-6.93)$ & 0.005 \\
\hline No physical activity (sedentary) & 136 & 83.5 & $1.10(0.67-1.82)$ & 0.707 \\
\hline
\end{tabular}

Note: The weighting of data can result in rounding discrepancies or totals not adding.

rently unaware of, or unable to access, podiatry services in Australia.

\section{Conclusion}

The findings of this population-based study indicate that approximately $10 \%$ of the general population has consulted a podiatrist in the past 12 months. Those who attend podiatry are more likely to be female, be aged over 45 years, be obese, and have major chronic medical conditions. The large proportion of people who report foot pain but have not accessed podiatry services (82\%) suggests that there may be a need to further promote podiatry services to the general community, particularly to men and younger people.

\section{Competing interests}

HBM is Editor-in-Chief of the Journal of Foot and Ankle Research. It is journal policy that editors are removed from the peer review and editorial decision making processes for papers they have co-authored.

\section{Authors' contributions}

AWT, TKG, and CLH conceived the study design, TKG conducted the statistical analysis, HBM and CLH inter- 
Table 5: Multivariate predictors of not accessing podiatry services in the last 12 months in people who reported foot pain.

\begin{tabular}{|c|c|c|}
\hline Variable & Odds ratio $(95 \% \mathrm{Cl})$ & $p$ value \\
\hline \multicolumn{3}{|l|}{ Sex } \\
\hline Female & 1.00 & \\
\hline Male & $2.11(1.27-3.50)$ & 0.004 \\
\hline \multicolumn{3}{|l|}{ Age } \\
\hline 75 years and over & 1.00 & \\
\hline 65 to 74 years & $1.94(0.97-3.88)$ & 0.061 \\
\hline 55 to 64 years & $3.53(1.72-7.26)$ & 0.001 \\
\hline 45 to 54 years & $4.26(2.09-8.67)$ & $<0.001$ \\
\hline 35 to 44 years & $5.42(2.19-13.42)$ & $<0.001$ \\
\hline 20 to 34 years & I5.08 (4.80-47.34) & $<0.001$ \\
\hline
\end{tabular}

preted the results, HBM drafted the manuscript, and all authors read and approved the final manuscript.

\section{Acknowledgements}

This study received financial support from a grant from Human Services Research and Innovation Program (large projects) 2000-0I, Department of Health, South Australia. HBM is currently a National Health and Medical Research Council fellow (Clinical Career Development Award, ID: 433049). We would also like to acknowledge the contribution of the NWAHS staff and participants.

\section{References}

I. Garrow AP, Silman AJ, Macfarlane GJ: The Cheshire Foot Pain and Disability Survey: a population survey assessing prevalence and associations. Pain 2004, I I 0:378-384.

2. Hill CL, Gill T, Menz HB, Taylor AW: Prevalence and correlates of foot pain in a population-based study: the North West Adelaide Health Study. J Foot Ankle Res 2008, I:2.

3. Greenberg L, Davis H: Foot problems in the US. The $\mathbf{1 9 9 0}$ National Health Interview Survey. J Am Podiatr Med Assoc 1993, 83:475-483.

4. Brodie BS, Rees CL, Robins DJ, Wilson AFJ: Wessex Feet: a regional foot health survey, Volume I: The survey. Chiropodist 1988, 43: I52-165.

5. Nancarrow SA: Reported rates of foot problems in rural south-east Queensland. Australas J Podiatr Med I999, 33:45-50.

6. Dunn JE, Link CL, Felson DT, Crincoli MG, Keysor JJ, McKinlay JB: Prevalence of foot and ankle conditions in a multiethnic community sample of older adults. Am J Epidemiol 2004, | 59:49|-498.

7. Benvenuti F, Ferrucci L, Guralnik JM, Gangemi S, Baroni A: Foot pain and disability in older persons: an epidemiologic survey. $\mathrm{J} \mathrm{Am}$ Geriatr Soc 1995, 43:479-484.

8. Leveille SG, Bean J, Bandeen-Roche K, Jones R, Hochberg M, Guralnik $J M$ : Musculoskeletal pain and risk of falls in older disabled women living in the community. J Am Geriatr Soc 2002, 50:67I-678.

9. Barr ELM, Browning C, Lord SR, Menz HB, Kendig H: Foot and leg problems are important determinants of functional status in community dwelling older people. Disabil Rehabil 2005, 27:917-923.

10. Keysor J], Dunn JE, Link CL, Badlissi F, Felson DT: Are foot disorders associated with functional limitation and disability among community-dwelling older adults? J Aging Health 2005, 1 7:734-752.

II. Bowling A, Grundy E: Activities of daily living: changes in functional ability in three samples of elderly and very elderly people. Age Ageing 1997, 26: 107-I I4.

12. Gorter KJ, Kuyvenhoven MM, deMelker RA: Nontraumatic foot complaints in older people. A population-based survey of risk factors, mobility, and well-being. I Am Podiatr Med Assoc 2000, 90:397-402.
13. Chen J, Devine A, Dick IM, Dhaliwal SS, Prince RL: Prevalence of lower extremity pain and its association with functionality and quality of life in elderly women in Australia. J Rheumatol 2003, 30:2689-2693.

14. Menz HB, Tiedemann A, Kwan MMS, Plumb K, Lord SR: Foot pain in community-dwelling older people: an evaluation of the Manchester Foot Pain and Disability Index. Rheumatology 2006, 45:863-867.

15. Balint GP, Korda J, Hangody L, Balint PV: Foot and ankle disorders. Best Pract Res Clin Rheumatol 2003, I 7:87-I II.

16. Korda J, Balint GP: When to consult the podiatrist. Best Pract Res Clin Rheumatol 2004, I 8:587-6I I.

17. Jones CL: Who treats feet? J Am Podiatr Med Assoc 1995, 85:293-294.

18. Williams AE, Bowden AP: Meeting the challenge for foot health in rheumatic diseases. Foot 2004, I 4: I54-158.

19. Helliwell PS: Lessons to be learned: review of a multidisciplinary foot clinic in rheumatology. Rheumatology 2003, 42: 1426-1427.

20. Redmond AC, Waxman R, Helliwell PS: Provision of foot health services in rheumatology in the UK. Rheumatology 2006, 45:57I-576.

21. Mirmiran R, Page JC, Armstrong JR, Killian R: Barriers to podiatric care among diabetic patients in the San Francisco Bay area. J Foot Ankle Surg 2000, 39:301-304.

22. Winocour PH, Morgan J, Ainsworth A, Williams DRR: Association of British Clinical Diabetologists (ABCD): survey of specialist diabetes care services in the UK, 2000. 3. Podiatry services and related foot care issues. Diabet Med 2002, I 9 (Suppl. 4):32-38.

23. White EG, Mulley GP: Footcare for very elderly people: a community survey. Age Ageing 1989, I8:275-278.

24. O'Dea G, Kerrison HS, Pollock MA: Access to health care in nursing homes: a survey in one English Health Authority. Health Soc Care Community 2000, 8: I80-185.

25. McGrother CW, Clarke M: Chiropody services: need, associated disabilities and utilisation. Community Med 1988, I0:|4- I8.

26. Gorter K, Kuyvenhoven M, DeMelker R: Health care utilisation by older people with non-traumatic foot complaints. What makes the difference? Scand J Prim Health Care 2001, 19:191-193.

27. Munro BJ, Steele JR: Foot-care awareness. A survey of persons aged 65 years and older. J Am Podiatr Med Assoc 1998, 88(5):242-248.

28. Harvey I, Frankel S, Marks R, Shalom D, Morgan M: Foot morbidity and exposure to chiropody: population based study. $B M J$ 1997, 3 15:1054-1055.

29. Australian Bureau of Statistics: National Health Survey: Summary of results (4364.0). Canberra, Australian Bureau of Statistics; 2006.

30. Grant JF, Chittleborough CR, Taylor AW, DalGrande E, Wilson DH, Phillips PJ, Adams RJ, Price K, Gill T, Ruffin RE: The North West Adelaide Health Study: detailed methods and baseline segmentation of a cohort for selected chronic diseases. Epidemiol Perspect Innov 2006, 3:4.

31. Australian Bureau of Statistics: National Health Survey: Users Guide (4363.0.55.00I). Canberra , Australian Bureau of Statistics; 2001.

32. Hosmer D, Lemeshow S: Applied Logistic Regression. 2nd edition. New York, John Wiley \& Sons; 2000.

33. Meyers L, Gamst G, Guarino A: Applied Multivariate Research. Design and Interpretation. Los Angeles, Sage; 2006.

34. Australian Institute of Health and Welfare: Podiatry labour force 2003. Canberra, Australian Institute of Health and Welfare; 2006.

35. Health and Social Care Information Centre: NHS Chiropody services summary information for 2004-2005, London.

36. Leveille SG, Guralnik JM, Ferrucci L, Hirsch R, Simonsick E, Hochberg MC: Foot pain and disability in older women. Am J Epidemiol 1998, I 48:657-665.

37. Garrow AP, Papageorgiou AC, Silman AJ, Thomas E, Jayson MIV, Macfarlane G]: Development and validation of a questionnaire to assess disabling foot pain. Pain 2000, 85: $107-1 \mid 3$.

38. Bennett PJ, Patterson C, Wearing S, Baglioni T: Development and validation of a questionnaire designed to measure foothealth status. J Am Podiatr Med Assoc 1998, 88:419-428. 